\title{
Erratum to: A mixed breadth-depth first strategy for the branch and bound tree of Euclidean $k$-center problems
}

\author{
Hatem A. Fayed • Amir F. Atiya
}

Published online: 28 September 2012

(C) Springer Science+Business Media New York 2012

\section{Erratum to: Comput Optim Appl \\ DOI 10.1007/s10589-012-9503-x}

The affiliations are incorrect, the correct ones are:

For Hatem A. Fayed:

Faculty of Engineering, Department of Engineering Mathematics and Physics, Cairo University, Giza, Egypt

For Amir F. Atiya:

Faculty of Engineering, Department of Computer Engineering, Cairo University, Giza, Egypt

On p. 4, under "A branch and bound approach" section, 5th line: "left node" has to be "leaf node".

The online version of the original article can be found under doi:10.1007/s10589-012-9503-x.

H.A. Fayed $(\varangle) \cdot$ A.F. Atiya

Faculty of Engineering, Department of Computer Engineering, Cairo University, Giza, Egypt e-mail: h_fayed@eng.cu.edu.eg

A.F. Atiya

e-mail: amiratiya@link.net 